\title{
Democracia y conflicto en contextos pluralistas: entrevista con Chantal Mouffe
}

\author{
Democracy and conflict in pluralist contexts: \\ an interview with Chantal Mouffe
}

Entrevista con:

\section{Chantal Mouffe}

Profesora e investigadora, Centre for the Study of Democracy/ University of Westminster.

chantalmouffe@compuserve.com

Concedida a:

\section{Aura Helena Ramos}

Profesora, Faculdade de Educação e Programa de Pós-graduação em Educação, Cultura e Comunicação em Periferias Urbanas/Universidade do Estado do Rio de Janeiro. Rua São Francisco Xavier, 524 20550-900 - Rio de Janeiro - RJ

- Brasil

aura@uerj.br

\section{Anna Luiza A. R.} Martins de Oliveira

Profesora, Programa de Pósgraduação em Educação Contemporânea/Universidade Federal de Pernambuco (UFPE). Av. Professor Moraes Rego, 1235 50670-901 - Recife - PE - Brasil alarmo@uol.com.br

Gustavo Gilson S. de Oliveira

Profesor, Programa de Pósgraduação em Educação Contemporânea/UFPE.

Av. Professor Moraes Rego, 1235 50670-901 - Recife - PE - Brasil gustavo.soliveira@ufpe.br

Rui Gomes de Mattos de Mesquita

Profesor, Programa de Pósgraduação em Educação/UFPE. Av. Professor Moraes Rego, 1235 50670-901 - Recife - PE - Brasil gomesdemattosdemesquita.rui@ gmail.com
RAMOS, Aura Helena et al. Democracia y conflicto en contextos pluralistas: entrevista con Chantal Mouffe. História, Ciências, Saúde Manguinhos, Rio de Janeiro, v.21, n.2, abr.-jun. 2014, p.749-763.

\section{Resumen}

Chantal Mouffe, junto al teórico político argentino Ernesto Laclau (1935-2014), lanzó, en 1985, las bases de la teoría del discurso. Luego, desarrolló su trabajo en el sentido de profundizar como influyen las formulaciones de la teoría del discurso en el análisis de las democracias contemporáneas. Abordando el conflicto como una producción del encuentro de la diferencia, Mouffe lo comprende como un aspecto indeleble en la constitución del social. En este encuentro con la autora, buscamos reflexionar algunos temas y problemáticas centrales de su trabajo, y las implicaciones de su teoría en el campo educacional contemporáneo.

Palabras clave: Chantal Mouffe (1943- ); teoría del discurso; democracia pluralista; derechos humanos; cultura.

\section{Abstract}

Chantal Mouffe, along with Argentinian political theorist Ernesto Laclau (19352014), laid down the bases of discourse theory in 1985. She later developed her work by exploring in more detail how discourse theory formulations influence the analysis of contemporary democracies. Approaching conflict as a product of the encounter with difference, Mouffe sees it as an indelible part of the constitution of social relationships. In this encounter with the author, we seek to reflect upon certain themes and problematics that are central to her work, and upon the implications of her theory for the field of contemporary education.

Keywords: Chantal Mouffe (1943- ); discourse theory; pluralist democracy; human rights; culture. 
¿ ${ }^{\text {s posible creer aún en la viabilidad de la democracia en el contexto de sociedades atra- }}$ las observadas en el mundo globalizado actual? En ese contexto, ¿qué modelo o proyecto de democracia podría conquistar y mantener el interés y el compromiso de ciudadanos y ciudadanas de diferentes orígenes, intereses, creencias e inclinaciones? ¿Cómo y hasta qué punto el ideal democrático aún coincide, o incluso, es compatible con la defensa de valores como la dignidad humana, los derechos humanos, la igualdad o la justicia social? Las protestas, levantamientos y manifestaciones en masa que se han estado produciendo en Brasil y en diversos países en los últimos años ¿indican el agotamiento y el virtual fracaso de los actuales sistemas y modelos políticos o representan una señal de vitalidad y renovación de la política en la presente realidad? Esos son algunas de los principales asuntos debatidos a través del pensamiento social y de la filosofía política contemporánea y forman parte, también, de algunos de los temas centrales del trabajo de la profesora y teórica belga Chantal Mouffe, actualmente profesora de teoría política e investigadora del Centro de Estudios de la Democracia de la Universidad de Westminster en Inglaterra.

A mediados de la década de 1980, la profesora Mouffe escribió, junto al teórico político argentino Ernesto Laclau, el libro Hegemonía y estrategia socialista: hacia una radicalización de la democracia (1985), obra clásica en la cual fueron lanzadas las bases de la llamada teoría del discurso de Laclau y Mouffe. La teoría del discurso surgió en un contexto en el que atores políticos tradicionales, como sindicatos y partidos, así como concepciones economicistas y deterministas, como lucha de clases y revolución, parecían ya no ser capaces de expresar y comprender los dilemas y demandas que emergían en la realidad social. A partir de la articulación original entre las nociones gramscianas de hegemonía y lucha de posiciones con debates post-estructuralistas - especialmente derridianos - sobre el lenguaje, el juego simbólico de (des)construcción de la realidad y el carácter erradicable del antagonismo, la teoría del discurso propuso una comprensión innovadora sobre los procesos de constitución de las identidades, acciones y movimientos políticos, la cual tuvo un papel fundamental en el análisis y en el desarrollo posterior de los llamados "nuevos movimientos sociales". ${ }^{1}$

Luego de la publicación de Hegemonía y estrategia socialista, Chantal Mouffe desarrolló su trabajo en el sentido de procurar profundizar como influyen las formulaciones propuestas por la teoría del discurso en el análisis de las democracias contemporáneas, especialmente para comprender las relaciones entre democracia y pluralismo. En base a esas investigaciones, Mouffe desarrolló una importante distinción entre lo que ella denominó "lo político", dimensión del antagonismo radical e insuperable en la relaciones sociales, y "la política", el conjunto de instituciones, prácticas y discursos que buscan mediar y organizar la convivencia humana. En ese sentido, Mouffe ha elaborado una comprensión bastante original sobre las nociones de "agonismo" y "pluralismo agonístico", indicando la posibilidad/necesidad de desarrollar una concepción de democracia en que los conflictos puedan expresarse e, incluso, ser mantenidos a partir de un "consenso conflictivo" en torno a principios ético-políticos

\footnotetext{
${ }^{1}$ En contraste con los movimientos sociales "tradicionales", como sindicatos y partidos de masa, con actuación predominantemente centrada en la estructura económica en el Estado, los llamados "nuevos movimientos sociales" (feministas, negros, indígenas, LGBT, ambientalistas, alterglobalistas etc.) se caracterizan, entre otros aspectos, por su actuación relacionada principalmente a demandas identitarias y culturales.
} 
mínimos. Abordando el conflicto como una producción del encuentro de la diferencia en contextos pluralistas, la investigadora lo comprende como un aspecto inerradicable en la constitución de lo social y pondera que su manifestación se da por una tensión que no implica la destrucción del otro, sino que se sustenta por medio de un diálogo continuo. Es así como coloca las bases para que pensemos en la política democrática como práctica de negociación de la diferencia y no como un espacio de superación de los conflictos. En la concepción de Mouffe, la democracia no es el alcance del estado de equilibrio e igualdad anhelado como el "ideal" liberal o la "utopía" del pensamiento crítico. Su comprensión agonística de democracia busca el establecimiento de consensos, pero entiende que al no suponer la erradicación de la diferencia serán siempre provisorios, ya que se exigirán canales permanentes de negociación con el "otro".

Esas elaboraciones teóricas pueden ser observadas en trabajos como El retorno de lo político (1993), La paradoja democrática (2000), En torno a lo político (2005) y, más recientemente, Agonistics: thinking the world politically (2013), en el cual amplía el debate para discutir sobre relaciones internacionales, cosmopolitismo y multilateralismo.

La entrevista a continuación fue concedida por la profesora Chantal Mouffe a un grupo de profesoras/es brasileños de la Universidad del Estado de Rio de Janeiro y de la Universidad Federal de Pernambuco que trabajan con la teoría del discurso en el campo de la educación y forman parte de la recién criada Red Latinoamericana en Teoría del Discurso. La entrevista fue realizada en Rio de Janeiro, en el mes de agosto de 2013, durante un período en el cual Chantal Mouffe y Ernesto Laclau participaban en una serie de actividades y eventos en Brasil. Abordando algunos temas y problemáticas centrales en el trabajo de la autora, los entrevistadores buscaron reflexionar sobre las implicaciones de su teoría en temáticas importantes del campo educacional contemporáneo, especialmente asuntos sobre violencia en la perspectiva de derechos humanos, diferencia y pluralismo étnico, cultural y religioso. A lo largo del debate, emergen también comentarios sobre otros asuntos actuales, tales como las recientes manifestaciones en masa ocurridas en Brasil y en el mundo, el trato a los inmigrantes y a los grupos étnicos minoritarios en Europa y los debates sobre cosmopolitismo y multipolaridad en las relaciones internacionales. La entrevista ofrece, de ese modo, una demostración oportuna e inequívoca sobre la relevancia, actualidad y vitalidad de la teoría del discurso y, en especial, sobre el pensamiento político de Chantal Mouffe.

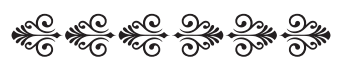

Han pasado veintiocho años desde que se publicó Hegemonia y estrategia socialista, la obra clásica que lanzó la teoría del discurso de Laclau y Mouffe. Analizando esa trayectoria ¿cuáles usted considera que fueron las principales contribuciones y nociones más productivas lanzadas por ese libro y que permanecen potentes hasta el día de hoy?

Bueno, yo creo que realmente la especificidad del enfoque que hemos desarrollado en Hegemonía y estrategia socialista, es poner juntos la tradición del post-estructuralismo con la tradición gramsciana. Somos los únicos que hemos hecho eso, porque hay gente que desarrolló 
la tradición gramsciana, hay otros que desarrollaron la tradición del post-estructuralismo, pero poner esas dos tradiciones juntas, eso es la especificidad de nuestra posición. Es por eso que los dos conceptos fundamentales son el del antagonismo y el de hegemonía. El concepto de antagonismo justamente es la base de una ontología post-fundacionalista en el cual, por ejemplo, la categoría de contingencia es absolutamente central y, también, la especificidad de la ontología que desarrollamos sobre la insistencia de una negatividad que sea de tipo radical. Eso está relacionado con el antagonismo, que es una negatividad que no puede ser nunca superada de manera dialéctica. Bueno, allí los puntos de referencia son, por una parte, el psicoanálisis y la visión del sujeto en Freud, pero también la perspectiva de Derrida, eso es un cierto tipo de ontología que es realmente muy específica, pero no únicamente al post-estructuralismo, aunque creo que ha sido mejor desarrollado en la tendencia postestructuralista. Entonces, la cuestión es pensar justamente ¿cómo pensar la política a partir de una ontología de ese tipo? Es allí, entonces, que viene la noción de hegemonía, ¿cierto?, si hay una negatividad radical, significa que todo orden es un orden precario, contingente, que es el resultado de ciertas prácticas que van a tratar de construir un orden, pero un orden que nunca tiene un fundamento, esa yo diría que es la diferencia entre lo que uno podría llamar un acercamiento anti-fundacionalista y post-fundacionalista. Porque la perspectiva anti-fundacionalista dice, bueno, "no hay fundamento". La posición del post-fundacionalista, es de decir, digamos, no hay un fundamento último, pero siempre hay tentativas de establecer unos órdenes que son órdenes precarios y contingentes, y esas prácticas que van a tratar de establecer un orden, de fijar las relaciones sociales, de establecer lo que nosotros llamamos, tomando la expresión de Lacan, de "points de capiton", eso es el objetivo de lo que nosotros llamamos las prácticas hegemónicas. Entonces, creo que eso es muy importante, ver cómo nuestra perspectiva política se refiere a un cierto tipo de ontología. Eso es lo que explica la diferencia entre nuestro enfoque y, por ejemplo, otros enfoques que hoy en día están bastante de moda como el de Antonio Negri y Michael Hardt. Eso es algo que me parece fundamental. Por ejemplo, en mi trabajo posterior he partido de esa concepción ontológica y lo he desarrollado en una dirección que establece una distinción que no está en Hegemonía y estrategia socialista, que es la distinción entre lo que llamo LO político y LA política. LO político se refiere a la dimensión del antagonismo y de la negatividad radical, se sitúa al nivel ontológico y LA política se refiere al conjunto de prácticas y discursos cuyo objetivo es organizar la coexistencia humana pero en condiciones que son siempre conflictivas porque son atravesadas por la dimensión de LO político.

\section{¿Hoy usted pondría en otros términos algún aspecto de esa discusión teórica?}

Yo no pienso que tendría que ser formulado de otra manera, y me parece que, realmente, hoy en día es muy importante para poder pensar la política de una manera adecuada, para criticar, por una parte, toda la ideología del consenso, toda la perspectiva neoliberal que dice que no hay alternativa, porque cuando uno parte de nuestro enfoque siempre hay alternativas. Todo orden se construye sobre la base que otros órdenes hubieran podido ser posibles y excluye otras posibilidades. A partir de esa perspectiva se puede criticar no solamente el pensamiento liberal dominante, como también un cierto tipo de pensamiento radical que defiende la posibilidad de llegar, en ciertas condiciones, a una sociedad completamente 
reconciliada. Contrariamente al pensamiento liberal, reconocen que en la sociedad actual hay antagonismos, pero ellos piensan que es posible llegar a una sociedad sin antagonismos. La especificidad nuestra es, precisamente, de criticar el consenso al centro pero también la idea de que es posible una democracia absoluta. Eso me parece muy vigente hoy en día y ayuda a entender muchos fenómenos importantes, aunque el libro fue escrito en 1985 y los contextos evidentemente son distintos. Por ejemplo, el momento en el cual escribimos el libro, el neoliberalismo estaba empezando aunque todavía estábamos bajo una hegemonía social demócrata, así es que el contexto era distinto, pero hoy en día me parece que se ha mostrado la vigencia, la perspectiva teórica que desarrollamos en Hegemonía y estrategia socialista. Hubo cambios muy importantes en el mundo, desde la caída del comunismo y la globalización neoliberal. Entiendo que esas dos perspectivas - de antagonismo y hegemonía - son pertinentes para entender esos cambios.

Sí, justamente queríamos que nos hablara respecto a la perspectiva de la democracia pluralista que, por ejemplo, ha orientado nuestras reflexiones sobre derechos humanos. Pensar en derechos humanos en una perspectiva agonística nos llevó a rechazar de manera radical las pretensiones universalistas (o universalizantes) que marcan el discurso de esa área. Buscamos un enfoque que, sin escapar del debate sobre condiciones de diálogo en relación a la diferencia que el área impone, piense ese diálogo como conflictual. Se trata de un diálogo que no pretende llevar al otro hacia una posición supuestamente universal, fija y homogénea, admite el carácter siempre contingente, precario, no literal de los sentidos que produce. En los términos de su teoría, ese diálogo afirma la imposibilidad de plenitud del consenso y de la propia hegemonía por medio de las nociones de consenso conflictuoso y hegemonía contingente. Así, la diferencia es admitida y asumida como una dimensión constitutiva y, por lo tanto, como algo que no se puede erradicar de lo social, no como algo a ser superado o eliminado frente a un universal que supuestamente daría cuenta de todo. Los derechos humanos serían, entonces, un significante vacío. ¿Considera usted que su reflexión sobre un mundo pluripolar y una perspectiva pluriuniversal sobre cultura modifican de alguna manera esa crítica al universalismo y a la concepción de los derechos humanos como significante vacio? En otros términos, admitir la posibilidad de "muchos universales", todos legítimos, ¿modifica las relaciones entre particular y universal, establecidas en sus otros trabajos?

Esa cuestión me parece que tengo que contestarla a dos niveles y dos contextos muy distintos. El consenso conflictual es algo que se refiere a la política al nivel de una asociación política. Yo, por ejemplo, he insistido mucho en que en un mundo multipolar no puede haber un consenso conflictual, porque el consenso conflictual implica la aceptación de un consenso en relación a principios ético-políticos, por ejemplo libertad, igualdad para todos. Por cierto hay interpretaciones distintas, pero es necesario que exista una asociación política. En el mundo multipolar eso no existe, porque lógicamente lo que es especifico del mundo multipolar, y mi crítica al cosmopolitismo viene justamente de allí, es que si se quiere realmente reconocer el pluralismo a nivel global, se acepta que esa comunidad internacional no existe verdaderamente, porque va a haber siempre distintos valores en las diferentes culturas. Por lo tanto, la lucha agonística, estrictamente dicho, solo se puede dar a nivel de la asociación política, y es únicamente de una manera de analogía que se puede hablar de un mundo multipolar que sea agonístico. Para hablar de la cuestión de los derechos humanos, yo diría 
que a nivel de una asociación política donde exista la democracia pluralista al estilo occidental, si uno piensa en cómo podría existir una forma de democracia agonística entonces, hay que reconocer la posibilidad de una lucha hegemónica para entender de manera distinta los derechos humanos. El consenso conflictual consiste en reconocer los derechos humanos como un elemento fundamental de nuestra forma de vida, algo que proviene de la tradición liberal, pero que también habrá una lucha sobre cómo entender esos derechos humanos. No hay, por lo cierto, un sólo sentido de los derechos humanos y, puede haber interpretaciones más progresistas que otras, puede haber, por ejemplo, la concepción, yo diría, radicaldemocrática de los derechos humanos. Será, evidentemente, muy distinta de la tradición liberal conservadora. Al interior de una asociación política, donde hay acuerdos sobre un cierto vocabulario de los derechos humanos, existirá, entonces, una lucha hegemónica respecto de cómo entender exactamente esos derechos humanos y también el tipo de instituciones que son necesarias para institucionalizarlos. Pero, cuando uno ya pasa al nivel internacional, yo creo que las cosas son distintas, y mi posición sobre eso es de decir que el lenguaje occidental de derechos humanos es solamente un posible lenguaje, una posible tradición entre otros. En relación a eso, Raimundo Panikkar dice que hay que preguntarse ¿qué es lo que está en juego en el lenguaje de los derechos humanos? Para él lo que está en juego es el reconocimiento de la dignidad de la persona. Nosotros occidentales tenemos un cierto vocabulario para hablar de eso, pero lo que hay que buscar es lo que Panikkar llama equivalentes homeomórficos de esos derechos. Eso significa que otras culturas pueden utilizar otro lenguaje, otros conceptos para referirse a la dignidad de la persona. Entonces, es muy erróneo, de parte de los occidentales, decir que la gente que no utiliza nuestro vocabulario no tiene sentido de los derechos, de la dignidad humana. Yo no diría que a ese nivel se pueda dar una lucha agonística. La lucha agonística es una lucha hegemónica, es una lucha para justamente tratar de fijar un cierto sentido al interior de una tradición determinada. Pero a nivel internacional, es muy importante reconocer el pluralismo de las tradiciones. Yo no creo que, por ejemplo, uno deba defender la idea de una lucha agonística entre la concepción occidental y otras concepciones, porque hay que reconocer la diferencia y aceptar que otras culturas traten los problemas de otra manera. No me parece que haya que pensar, a nivel internacional, el desarrollo de la democracia como el proceso por el cual una sola visión llegue a ser hegemónica. Es precisamente lo que estoy criticando, y lo que pasa hoy en día con el Occidente tratando de imponer su concepción de los derechos humanos, presentándolo como la concepción que tiene que ser aceptada por todo el mundo. Esa es la visión del cosmopolitismo, que hay una sola concepción, que esa concepción es la mejor, la más moral, las más racional, y que todos los seres humanos, en tanto seres humanos, tienen que aceptarla. Es necesario reconocer la especificidad de las culturas y aceptar que el mundo es un pluriverso, no es un universo. Eso significa aceptar la (visión) de (las) distintas tradiciones según el papel, por ejemplo, de la religión, porque cada vez está más reconocido que nuestro lenguaje de derechos humanos es algo que ha sido muy influenciado por la tradición judío-cristiana y por la reforma protestante. Eso es parte de nuestra historia, pero nuestra historia no es la única y hay que reconocer la posibilidad y la legitimidad de otras culturas. 
Sí, entendemos y estamos de acuerdo con usted al exponer que no es posible analizar la cuestión de la diferencia a nivel internacional del mismo modo como la abordamos en el plano local, por ejemplo, en la escuela... Sin embargo, al operar con la perspectiva agonística, hemos sido llevados a una afirmación, digamos, radical, en relación al carácter contingente y provisorio de las identidades. Pedimos, entonces, a partir de nuestra conversación, su contribución respecto a esos aspectos que son centrales en nuestro trabajo, que nos diga si su reflexión, de alguna manera, posibilita pensar que no existe una totalidad global, pero que puede admitir pequeñas totalidades fijadas en diferentes partes del mundo. Frente a eso, ¿cómo abordar la cuestión de lo "universal"?

Yo diría que al interior de lo que llamamos el mundo occidental hay una lucha agonística para entender los derechos humanos de manera más liberal, más progresista, aún así, si tú piensas, por ejemplo, en la tradición china u otras, habrá también luchas internas al interior de esas culturas, que no son culturas estáticas, evidentemente, esas no son mónadas completamente separadas. Aunque a mí no me gusta mucho ese término, hibridización, tengo que decir que las culturas se influencian las unas a las otras, entonces, hay aporte de alguna manera. Tú puedes importar ciertas cosas, no con el objetivo de crear una visión homogénea. Eso es lo que me parece importante, reconocer las diferencias y, evidentemente, no son diferencias completamente separadas, son diferencias que se van transformando por el contacto, pero, lo que me parece fundamental es abandonar la idea de que hay que tener una visión homogénea.

¿Las relaciones entre agonismo y antagonismo podrían ser pensadas como interdependientes y mutuamente constitutivas? Una de las discusiones más productivas de sus trabajos es la comprensión de las relaciones entre antagonismo y agonismo, donde analiza el agonismo como una forma específica de emergencia de los antagonismos en los límites de una comunidad política. ¿Considera posible pensar en relaciones antagónicas más agonísticas o menos agonísticas, como dos polos de un eje continuo?

Sí, estoy completamente de acuerdo. Por ejemplo, yo creo que no hay una diferenciación fundamental de naturaleza entre antagonismo y agonismo. Yo siempre insistí en que hay antagonismo en el agonismo, no es una eliminación... Yo creo que el antagonismo es inerradicable y que el agonismo es una forma de sublimación. El antagonismo está allá, pero está "puesto en escena" de manera tal que los oponentes no se van a tratar como enemigos sino como adversarios. Estoy de acuerdo que antagonismo y agonismo hacen parte de un mismo continuo, no son cosas completamente distintas. En ciertas circunstancias, el agonismo va a tener una característica más antagonística y otras veces menos, las circunstancias históricas son muy importantes, por ejemplo, uno ve en América Latina... hay situaciones que son más antagonísticas que en Europa. El grado de agonismo depende mucho de situaciones históricas concretas y determinadas, pero es cierto que siempre van ligados, sí. Quiero insistir en que nunca hay una separación completa entre antagonismo y agonismo. El agonismo es una forma de antagonismo, por eso es que a veces me refiero al antagonismo estrictamente y después al agonismo como una forma de antagonismo democrático, la forma que toma el antagonismo en una política democrática. 
Basándonos en su obra, comprendemos que en las sociedades contemporáneas, con sus múltiples atores sociales, existe cada vez más la necesidad de reconocer el carácter político de las fronteras definidoras del espacio público y sus instituciones democráticas. Tales fronteras son constitutivas de una cultura política dominante y, de manera no extraña, rechazan lógicas y valores que les vengan a amenazar la integridad. ¿Cómo es posible para usted pensar, en términos de una decisión éticopolítica, la defensa de transformación de los antagonismos en agonismos?

No hay que plantear la cuestión de transformar el antagonismo en agonismo como una cuestión normativa, pero de la manera siguiente: Si aceptamos que la dimensión del antagonismo es inerradicable, y que una de sus formas de manifestarse es en la relación amigo/ enemigo, entonces, la pregunta es ¿es posible pensar a partir de esas premisas la posibilidad de una sociedad democrática? Es el tema que desarollé en relación con el pensamiento de Carl Schmitt para quien la democracia pluralista es un régimen no viable, porque reconocer el antagonismo implica ver que, contrariamente a lo que pretende la democracia pluralista, no es posible legitimar el conflicto al interior de una sociedad. Sin duda, si se legitima el conflicto concebido al modo amigo/enemigo se puede llegar a la guerra civil y, por eso, afirma Schmitt, se necesita un Estado fuerte. Al otro extremo se encuentra el pensamiento liberal, en el sentido amplio que incluye pensadores como Habermas, según el cual, para poder pensar la democracia pluralista, es necesario negar la dimensión del antagonismo. De los dos lados se postula que hay una incompatibilidad entre el hecho del antagonismo y la democracia liberal. La cuestión que me preocupa, es la siguiente: a partir de la posición teórica que hemos defendido en Hegemonía, ¿cómo es posible pensar la democracia pluralista? ¿En qué condición es posible? Mi respuesta consiste en decir que la solución requiere entender que el antagonismo puede tomar la forma de un agonismo. No es una respuesta de tipo normativo, es afirmar que la democracia pluralista es posible con la condición de que existen las instituciones que permitan transformar el antagonismo en agonismo.

Entiendo, el asunto se relaciona con la comprensión de cómo lo social se constituye, cómo las relaciones se dan, y no en base a cómo las relaciones deben ser y se deben desarrollar.

Exactamente, defender la democracia es una decisión ético-política, esa decisión no se da al nivel de la transformación del antagonismo en agonismo, sino al nivel de decir queremos construir una sociedad democrática. La otra cuestión es una vez tomada esa decisión ¿cómo se puede construir esa democracia? La respuesta acá es de tipo pragmático y consiste en imaginar cómo transformar el antagonismo en agonismo.

La perspectiva del pluralismo agonístico es evocada frecuentemente para analizar contextos macropolíticos, relacionados con los Estados nacionales y/o las relaciones internacionales. ¿Considera usted que sería posible y productivo desarrollar los insights de la perspectiva agonística para investigar la realidad de instituciones sociales más específicas y contextuales, como la escuela, la Iglesia, los movimientos sociales?

La perspectiva agonística es la respuesta a la cuestión de cómo crear la democracia en una situación en la cual uno reconoce que el conflicto es inerradicable. Pero la perspectiva agonística no está pensada principalmente al nivel macro-político. Mi modelo agonístico ha sido desarrollado para pensar cómo crear un orden social que sea democrático y que reconozca 
el conflicto, pero, evidentemente, eso es al nivel de una asociación política, es únicamente de manera analógica que yo después he desarrollado la idea del mundo multipolar a partir de una crítica del cosmopolitismo. Me parecía que el problema con el cosmopolitismo era que estaba en contradicción con la perspectiva nuestra de antagonismo y hegemonía, porque el cosmopolitismo supone que haya un orden posible más allá de la hegemonía, más allá del antagonismo. A partir de mi perspectiva teórica no puedo ser cosmopolita y me pregunté ¿no habrá en la perspectiva agonística algunos elementos que puedan ser útiles para pensar las relaciones a nivel internacional? Mi respuesta es proponer una pluralización de hegemonías en un mundo multipolar. Es solamente de manera analógica que uno puede hablar de un mundo multipolar agonístico, porque en un mundo multipolar no puede existir un consenso conflictual, pues de esa manera no sería realmente multipolar. Lo que yo veo de común en esos dos casos es insistir de que la mejor manera para impedir que emerjan formas de violencia, tanto al nivel nacional como a nivel internacional, es crear las instituciones, los canales que van a hacer eso posible, y cuando el conflicto emerge, que no vaya a tomar una forma antagonista. Por ejemplo, en mi libro On the political, yo he tratado de sugerir la idea de que el tipo de violencia específico de movimientos como Al-Qaeda tiene que entenderse en el contexto del mundo unipolar que los americanos estaban tratando de imponer, diciendo que los que no están con nosotros son enemigos y nosotros somos los civilizados. Una vez que no se reconoce a otras culturas la posibilidad de pensar la democracia a su manera, y se dice "ustedes tienen que ser como nosotros", si no existen canales legales de oponerse a esa imposición, es probable que la reacciones se van a manifestar a través de formas violentas. A ese nivel mi reflexión sobre agonismo y antagonismo tiene que ver con cómo manejarse con la violencia en el mundo, cómo hacer para minimizar la emergencia de esas formas de violencia. No pretendo que en un mundo multipolar se van a eliminar los conflictos, pero creo que en un mundo en el cual no haya una tentativa de un sector por imponer su concepción de las cosas, habrá menos tendencia de los oponentes a confrontarse de una manera violenta. En mi libro En torno a lo político hago mucha referencia a Elias Canetti en su libro Masa y potencia donde habla sobre la especificidad del sistema parlamentario y el desarrollo de la democracia parlamentaria. Él dice que el gran valor de la democracia parlamentaria, de ese tipo de democracia a través de las elecciones, es que antes se hacían guerras, porque no había la posibilidad de poner en escena el conflicto de una manera no violenta, mientras que ahora, que existen las elecciones, uno en vez de ir a la guerra, se puede oponer simbólicamente y en caso de conflicto decir "vamos a votar", y quien gana es como si hubiera ganado una batalla en la guerra.

Pensando en lo que dijo anteriormente entiendo que, por ejemplo, si "democracia" es un elemento importante, no es posible pensar en una única forma de entender "democracia" sino que existen diferentes formas de organización que pueden ser consideradas como democráticas en distintos espacios, o sea, que es admisible que diferentes tradiciones conciban el asunto de la democracia de modos distintos, así como dignidad humana, si usted piensa en derechos humanos...

Para que la democracia juegue ese papel, tiene que ser una democracia que dé la posibilidad de expresión a diferentes voces. Yo creo que hoy en día, por ejemplo, todos esos movimientos que uno ve, los de Brasil no los conozco suficientemente, pero me parece que en parte también 
se aplica eso acá, todos esos movimientos de protesta, son porque la democracia no funciona bien. Hay muchos grupos que no tienen la posibilidad de intervenir en las decisiones. En Europa, uno de los problemas es que los partidos de centro-izquierda y partidos de centro ofrecen la misma propuesta, eso no da la posibilidad de que la gente realmente tenga una voz. Por ejemplo, uno de los slogans de los movimientos de protesta en Europa, y me parece muy interesante, es "nosotros tenemos voto pero no tenemos voz" porque no basta tener voto, si solo se puede votar por partidos que ofrecen la misma cosa, eso no es realmente un voto, un voto tiene sentido en la medida en la cual se puede realmente escoger entre proyectos políticos distintos, si los partido ofrecen lo mismo, entonces se tiene voto pero no se tiene voz.

La perspectiva agonística es bastante productiva para pensar sobre el asunto de la representación dado que, incluso existiendo la posibilidad de haber propuestas políticas diferentes, tales proyectos son formulados en situaciones sociales que cambian de forma poco previsible, lo que refuerza esa idea de tener voto pero no tener voz como algo inherente al modelo de democracia liberal.

Justamente, eso es muy importante, y me parece que esos movimientos de protesta pueden ser entendidos mucho mejor a través de esa perspectiva agonística. Es la falta de una política agonística que lleva a la gente a esos movimientos, porque no tienen la posibilidad de hacerlo a través de los canales políticos, entonces, me parece que eso es realmente lo que está en juego.

Retomando el asunto anterior ¿usted considera que hay alguna dificultad teórica en la perspectiva agonística para abordar situaciones que son más contextualizadas, como Iglesia y escuela, por ejemplo?

Ese núcleo de la reflexión que está en la base de mi proyecto agonístico está pensado a nivel del Estado nacional, a partir de eso uno puede ver si también puede servir para pensar a nivel más macro, pero yo creo que también uno puede ir a niveles más micro, locales, pero nuevamente sería únicamente de una manera analógica, porque no se trata de aplicar la perspectiva de la democracia agonística allí, aunque eso puede permitir entender las dinámicas locales. Pero eso me lo puedes explicar tú, es algo con lo que ustedes trabajan, en el caso de la escuela, ¿cómo ves tú la posibilidad de pensar eso a nivel de la escuela?

Bueno, no sé si es por analogía que operamos con la perspectiva agonística para comprender asuntos relativos a la escuela, eso me parecería una reducción de la importancia y centralidad que ese abordaje ha tenido en nuestros estudios sobre escuela y sobre currículo. Como señalé, entendemos que sería inadecuado tomar esa construcción teórica como un modelo dirigido a determinar cómo las relaciones se deben dar - lo que usted está llamando de tentativa de normatización, y estamos de acuerdo con eso. Se trata de asumir una referencia analítica para abordar las relaciones sociales (que se dan en diferentes ámbitos) que es distinta de las perspectivas estructuralistas - liberales y críticas. Abordamos la escuela como una arena de disputas y nos importa comprender cómo, en este contexto de producción cultural, la diferencia se expresa, negocia significados y articula demandas - llamamos eso como proceso de constitución curricular...

Sí, pero es más, es justamente la dimensión de la hegemonía. Porque la lucha agonística y la lucha hegemónica no son exactamente la misma cosa. Claro que la lucha agonística es una forma de lucha hegemónica, pero no toda forma de lucha hegemónica es agonística. 
Sí, comprendemos que la escuela es una institución marcada por el discurso de establecimiento de consensos primordiales, una institución que busca ese consenso a partir de la afirmación de modelos (y conocimientos) enunciados como universales. El discurso de igualdad y ciudadanía en la escuela es el lema de la homogeneización. Al afirmar el antagonismo como elemento constitutivo de la democracia y rechazar la idea de un consenso que sea capaz de conciliar toda diferencia en torno de principios universales, estamos operando con la dimensión de "Lo Político", a partir de la cual buscamos comprender los mecanismos institucionales de expresión y silenciamiento de la diferenciaétnicas, religiosas, de orientación sexual, generacionales, de género, de constitución familiar etc. Pensar en los canales para expresar la diferencia, orientada por la perspectiva agonística, al interior de la escuela es algo que diferencia la mirada en relación a esa institución. Así, también situamos la educación en derechos humanos no como una práctica de conscientización y tolerancia, sino como un espacio de negociación de la diferencia - formas no violentas de establecer relaciones que serían necesariamente conflictuosas, puesto que la diferencia continúa existiendo, lo que es condición para lo que, junto con usted, llamamos de democracia radical y pluralista.

Sí, estoy de acuerdo, yo diría que el punto fundamental es reconocer que evidentemente algunos conflictos pueden ser resueltos, pero el objetivo no puede ser siempre establecer un consenso, sino vivir con nuestras diferencias y el reconocimiento del derecho del otro de tener su punto de vista. Yo creo que eso también es algo central, muy central en una perspectiva agonística. La perspectiva agonística es reconocimiento; hay conflicto, no nos vamos a poner de acuerdo, pero vamos a encontrar la manera de vivir juntos con esas diferencias, esa idea sí se puede aplicar en otros niveles.

El asunto de la convivencia de la diferencia es central también para los enfoques liberal y crítico orientados por la óptica del multiculturalismo y la perspectiva de la tolerancia. ¿Cómo distinguir el pluralismo agonístico de esos enfoques?

Yo creo que lo que está en cuestión es la manera cómo uno entiende el pluralismo, y hay una manera que yo diría que es la manera típicamente liberal de entender el pluralismo, es de decir, bueno, las diferencias existen, pero esas diferencias pueden ser todas acogidas. Refiriéndome a la línea de Weber y de Nietzsche, creo que reconocer el pluralismo implica reconocer también la inevitabilidad del conflicto, porque pensar que somos todos diferentes, pero podemos vivir todos muy contentos, ¡no! Allí donde hay pluralismo, hay posibilidad de conflicto. Hay muchos tipos de multiculturalismo, pero hay formas de multiculturalismo típicas que, justamente, implican una visión de un pluralismo que es sin antagonismo mientras que, el pluralismo agonístico reconoce fundamentalmente que donde hay pluralismo va a haber siempre posibilidad de conflicto y que la cuestión que se plantea es cómo hacer para que ese conflicto no tome una forma violenta sino una forma agonística y también reconocer, esa es una gran diferencia con el pluralismo de tipo liberal, que la sociedad siempre está instituida políticamente. Por lo tanto, también hay que plantearse la cuestión de los límites de pluralismo. Es allí donde yo veo una gran diferencia entre el tipo de pluralismo agonístico y otras visiones, es que algunos multiculturales van hasta el punto de plantear que debe existir un sistema de pluralismo legal. Por ejemplo, para ilustrar lo que quiero decir: hay gente en Inglaterra que defiende la posición de que la comunidad musulmana tendría que organizarse según sus propias instituciones y tener formas legales específicas. Defienden el pluralismo legal 
y afirman que una sociedad que es realmente pluralista, que es realmente multicultural, debe también organizar las formas de derecho que corresponden a cada comunidad. Con eso yo no estoy de acuerdo, porque una vez que tú reconoces que la sociedad siempre está constituida políticamente, eso implica necesariamente que habrá fronteras, que habrá límites. Para mí es una cuestión crucial, siempre habrá un momento en el cual hay que decir: esos son los límites porque hay demandas que no pueden ser tratadas como legítimas al interior de nuestra sociedad, esas demandas cuestionan los principios políticos que organizan esa sociedad. Reconocer que la sociedad esta instituida políticamente, significa reconocer que hay un cierto marco constitucional que es el marco al interior del cual se organiza la coexistencia humana, el consenso conflictual tiene que ver con eso. En ese consenso, sobre valores fundamentales que van a informar nuestra coexistencia, siempre está la posibilidad de que haya personas que no van a reconocer esos valores. Ellos no pueden ser considerados como adversarios legítimos, son enemigos. Para dar un ejemplo concreto, yo creo que un partido que se declara nazi, no debe poder participar en las elecciones, elegir representantes para la cámara.

Sí, es importante que usted aborde ese asunto que emerge al estar hablando a partir de la perspectiva agonística, es decir, ¿habrá un límite para admitir al otro como legítimo otro, como adversario con el cual es necesario negociar y no como un enemigo para ser destruido?

Sí, en relación a eso he discutido con mucha gente que no está de acuerdo conmigo, pero yo creo que una constitución, o un orden político siempre establecen un marco de legitimidad, lo que es legítimo y lo que no es legítimo y diría que sistemas conflictivos de legitimidad no pueden existir al interior de una asociación política sin necesariamente llevar a la destrucción de la asociación política, entonces, es muy importante reconocer los límites de la lucha o la confrontación agonística. Para que haya confrontación agonística se necesita una base de consenso, pero ese consenso básico debe permitir la existencia de un conflicto entre varias interpretaciones, por eso es un consenso conflictual. Es evidente, por ejemplo, si uno toma los valores de libertad e igualdad para todos, que son los principios que denomino de ético-políticos de la democracia pluralista, mucha gente puede estar de acuerdo con esos principios al mismo tiempo que los interpreta de manera muy diferente y hasta conflictiva. Pero en este caso son adversarios porque existe, hay un campo simbólico común entre ellos. Por el contrario los que declaran "hay que acabar con la democracia pluralista y establecer un orden teocrático", ellos, evidentemente, no son adversarios, son enemigos. Por eso, el pluralismo agonístico reconoce que siempre hay límites, no se puede, en nombre del pluralismo dar la posibilidad que los enemigos del pluralismo lo pongan en duda de una manera legítima, eso para mí es muy importante. Hay una primacía de la dimensión política, porque la dimensión política es lo que permite la institución de la sociedad y eso es lo que los liberales no reconocen, los liberales ven el terreno como un terreno neutro. Otro punto importante es reconocer que la lucha agonística se da al interior de ciertas fronteras pero que también puede tener que ver con la transformación de las fronteras. Por ejemplo, el proyecto de radicalización de la democracia es un proyecto que tiene que ver con la transformación de las instituciones, porque esa visión agonística no es una visión puramente institucionalista en el sentido de considerar que las instituciones existentes no se pueden cambiar. Las instituciones proveen el marco, pero también la lucha es para transformar las instituciones, 
pero hay que hacerlo a través de ellas, se trata de la transformación de las instituciones. No significa destrucción, esa es la diferencia fundamental, diría yo, con una estrategia de política radical de tipo jacobino, proclamando que hay que acabar con la sociedad existente para crear algo totalmente distinto. Es lo que nosotros, utilizando la expresión de Gramsci, llamamos de "guerra de posición", la guerra hegemónica es una guerra de posiciones, es una guerra al interior del marco para desarticular, rearticular las instituciones. Eso me parece importante porque sino uno cae en una concepción liberal de estado neutro que no reconoce el carácter fundador del momento político, fundador en el sentido post-fundacionalista, como resultado de una cierta sedimentación de una hegemonía.

Volviendo a la pregunta sobre la distinción de ese enfoque en relación a la óptica del multiculturalismo, creo que la diferencia con el muticulturalismo liberal es que éste parte de una ontología muy distinta. El multiculturalismo liberal piensa un pluralismo sin antagonismo, el terreno social como un terreno neutro y, entonces, no hay en esa perspectiva toda esa dimensión de la primacía de lo político, de reconocer que las instituciones siempre son el resultado de la sedimentación de prácticas hegemónicas. Pero hay muchas formas de multiculturalismo, por ejemplo, hay mucha diferencia entre lo que sucede en Canadá y EEUU. En Canadá, encuentro muy problemática la manera cómo entienden el multiculturalismo. Yo tengo una amiga que es jueza y cuenta que allá, en nombre del multiculturalismo, están legitimando una serie de prácticas que son terriblemente ofensivas para las mujeres, y dicen; "¡ah! pero, esa es la cultura de ese grupo". Ella ha tenido que estar muchas veces en juicios donde, en nombre de la cultura, justificaban la violencia contra las mujeres.

Entiendo, eso se refiere a lo que usted indica como un nivel ético-político a partir del cual la democracia pluralista pueda existir. En Brasil, así como en diversos países de América Latina, un tema que ha emergido de manera relevante en relación al debate sobre multiculturalismo, es el de la religiosidad. En las últimas décadas, hemos vivido un intenso proceso de declive de la hegemonía católica tradicional en el campo religioso y de pluralización de las identidades, discursos y atores sociales en ese campo (evangélicos, neo-pentecostales, religiones de matriz africana, indígena, espiritualistas etc.). Ese movimiento de pluralización también está relacionado con la constitución de identidades y lógicas religiosas en el espacio público, tanto en los espacios políticos tradicionales (como partidos, gobierno y campañas electorales) como en espacios sociales menos explícitos políticamente (como los medios de comunicación, el mercado cultural y también las escuelas). Para algunos analistas, esa "eclosión" de discursos de origen religioso en el espacio público representaría inevitablemente un retroceso político y una amenaza para las conquistas civilizadoras de la democracia liberal. ¿Cómo usted analiza, a partir de las concepciones de la democracia radical y del pluralismo agonístico, ese llamado "retorno" de los discursos religiosos a los debates públicos y políticos en el mundo contemporáneo? ¿Es posible y legítimo vetar discursos religiosos en el espacio púbico en defensa de banderas como la laicidad del Estado o de la escuela pública? Por otro lado, ¿cómo lidiar con la multiplicidad de demandas y posiciones frecuentemente conflictivas, manifestadas por diferentes grupos religiosos, y con discursos preconizados por muchos líderes y sectores religiosos conservadores, muchas veces contrarios a las libertades civiles e incluso a los derechos humanos?

Bueno, en realidad, esa eclosión es un fenómeno particularmente brasileño, ¿cierto? Allí habría que hacer un análisis sociológico. Pero bueno, yo lo único que puedo decir sobre 
ese asunto es que hay que reconocer que una sociedad democrática no puede eliminar completamente la cuestión religiosa de la cuestión política y del espacio público. En algunos países muy laicos, como Francia, están tratando de hacer una separación, una exclusión de la religión de la esfera política. Pero me parece que si uno reconoce, eso es otra parte de mi trabajo que no hemos tocado acá, que una de las grandes motivaciones, que lleva a la gente a actuar políticamente, es lo que llamo de "pasiones", es decir, toda la dimensión de los afectos, contrariamente a lo que pretende la democracia pluralista y su importancia en la constitución de las identidades colectivas. Bueno, la religión es una gran fuerza de movilización de afectos, sobre ese punto mi posición ha cambiado. Al principio yo estaba más para decir que la religión no tiene lugar en la esfera pública, después me di cuenta que eso era una contradicción, que yo no podía, por una parte, insistir sobre la importancia de las pasiones y decir: "no, pero la religión no puede tener espacio al nivel de la política", con eso realmente excluía una enorme e importante fuente de pasiones. Entonces ahora sí, yo reconozco que es perfectamente legítimo, yo diría (eso liga con el punto anterior) que en la medida en que esas voces religiosas no estén en oposición con los fundamentos constitucionales, entonces sí son legítimas. Pero yo allí pondría la condición de que las demandas que hacen esos grupos se expresen dentro de un vocabulario, una forma que sea compatible con la constitución. Ahora, no sé cuál es la situación en Brasil respecto a eso en realidad.

Acá, por ejemplo, hay católicos, evangélicos, religión de matriz africana, indígena, ahora a mí lo que me interesa saber es ¿hay reivindicaciones que son propias de esos grupos, a nivel político? ¿O, no? Por ejemplo, yo he visto que la posición en Inglaterra, la posición no ha sido la de integrar realmente. Por otro lado, en Francia, la política es claramente de asimilación: "para ser francés hay que..." y eso evidentemente encuentra límites. Yo he visto la evolución de los dos países y es interesante ver que de alguna manera los franceses se han aproximado un poquito más al modelo inglés y el modelo inglés a los franceses, porque el modelo inglés es finalmente de no tratar realmente de integrar, ha creado una situación en la cual tú tienes guetos, enormes, y entonces, sucede que de pronto hay unos rayos, unas explosiones. Hace algunos años en el norte de Inglaterra hubo unos jóvenes pakistaníes que se revelaron, se examinó la situación y se dieron cuenta que ni siquiera hablaban inglés, era gente de la tercera generación de inmigrantes y no hablaban inglés porque vivían absolutamente en guetos. Otro ejemplo, una colega mía que vivió en la época, en la parte de Londres donde hay una comunidad bengalí muy grande, decía que era rarísimo, ella se sentía completamente en un país extraño, ella iba al shopping y la gente bengalí la miraba, es decir, hay un problema. Hay respetadas culturas y todo, pero hasta cierto punto, porque también hay que reconocer que ésta es una sociedad democrática y necesita que se cree una forma de identificación ciudadana. Tiene que ser evidentemente una ciudadanía agonística. Cierto tipo de teoría política tiene una visión de la ciudadanía como homogénea, del tipo: hay una sola manera de actuar como ciudadanos", entonces, "tenemos todos que actuar como ciudadanos" y, eso consiste en tener un modelo dominante. Yo creo que uno puede actuar como ciudadano de manera muy distinta según las posiciones en la lucha agonística, dependiendo de las formas de ejercicios de la ciudadanía que se dan de manera distintas, pero es necesaria esa dimensión de la ciudadanía. Yo creo que por una parte lo que está mal, o es peligroso, es querer imponer una sola visión de la ciudadanía, pero el otro extremo es de decir no, cada 
cultura tiene que seguir un modelo diferente. Eso, por ejemplo, es una cuestión que los ingleses han empezado a darse cuenta. Por ejemplo, algo que empezó con Tony Blair, que antes no existía, ceremonias cuando se recibe la nacionalidad británica, antes era simplemente un papel que iba firmado, algo práctico, ahora ante eso hay toda una cuestión simbólica de que "tú llegas a ser inglés", porque se dan cuenta de que es importante para la vida común.

Los puntos mencionados aquí tratan, de alguna forma, el tema de la violencia, relacionada con las preocupaciones de nuestro estudio sobre la escuela - que abordan asuntos religiosos; étnico-raciales; de género; de orientación sexual; del currículo de educación en derechos humanos etc. Inspirados en sus estudios, hemos entendido que la violencia no está en la existencia del conflicto sino en las formas destructivas de lidiar con la diferencia y con el conflicto que la existencia de la diferencia necesariamente genera. Pedimos que cierre este encuentro reflexionando un poco más sobre el tema de la violencia en la perspectiva de la democracia pluralista.

Tenemos que confrontar el problema de la violencia como algo que no se puede nunca eliminar, y que la idea de que la democracia no puede tener como objetivo el establecimiento del consenso, sino cómo manejarse con el disenso para evitar que se manifieste a través de la violencia, eso es fundamental en mi reflexión. Hay que reconocer que la posibilidad de violencia está siempre presente y preguntarse ¿cómo crear formas de organización social que puedan conjurar esa violencia? En la reflexión de la teoría política, desde Maquiavelo, siempre ha habido dos escuelas que reconocen la dimensión del antagonismo. Thomas Hobbes y Carl Schmitt son conscientes de que el ser humano es ambivalente, que tiene pulsiones muy altruistas, pero también otras que son destructivas. Algunos llaman a eso una antropología pesimista, pero yo diría que es una antropología realista, que los seres humanos no son así seres que tienen únicamente el deseo de concordia. Pero en general los que parten de ese tipo de visión llegan a la conclusión de que la única manera de impedir la explosión de antagonismos es imponer un orden autoritario. Los liberales piensan que si uno parte de esa perspectiva necesariamente uno llega a decir que la democracia no es posible y creen que, para que la democracia sea posible, es necesario negar el hecho del antagonismo. Pero eso no les permite entender una enorme cantidad de fenómenos políticos, porque esa dimensión antagonista es fundamental en la política. Para mí la cuestión, justamente, es dar una respuesta democrática a partir de premisas realistas. Hay que reconocer que el desafío fundamental para la democracia no es encontrar procedimientos para llegar a un consenso inclusivo. Hay que partir de una perspectiva realista y examinar ¿cómo se puede, en esas condiciones, pensar la posibilidad de una democracia pluralista? Esa es realmente la cuestión que está al centro de mi reflexión, cómo, a partir del reconocimiento del antagonismo, dar una respuesta democrática. La tarea fundamental es pensar la convivencia humana sin negar esa dimensión de antagonismo y del conflicto.

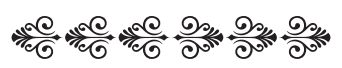

